\title{
Urinary cotinine levels and environmental tobacco smoke in mothers and children of Romania, Portugal and Poland within the European human biomonitoring pilot study
}

\author{
Ioana-Rodica Lupsa a,*, Baltazar Nunes ${ }^{b, 1}$, Danuta Ligocka ${ }^{c}$, Anca Elena Gurzau ${ }^{\text {a }}$, \\ Marek Jakubowski ${ }^{c}$, Ludwine Casteleyn ${ }^{\mathrm{d}}$, Dominique Aerts ${ }^{\mathrm{e}}$, Pierre Biot ${ }^{\mathrm{e}}$, Elly Den Hond ${ }^{\mathrm{f}}$, \\ Argelia Castaño ${ }^{i}$, Marta Esteban ${ }^{i}$, Marike Kolossa-Gehring ${ }^{j}$, Ulrike Fiddicke ${ }^{j}$,

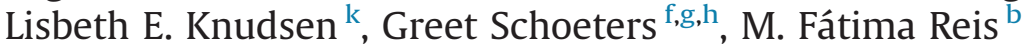 \\ a Environmental Health Center, 58 Busuiocului Street, 400240 Cluj-Napoca, Romania \\ ${ }^{\mathrm{b}}$ Instituto de Medicina Preventiva, Faculdade de Medicina da Universidade de Lisboa, Portugal \\ ${ }^{\mathrm{c}}$ Nofer Institute of Occupational Medicine, Lodz, Poland \\ ${ }^{\mathrm{d}}$ University of Leuven, Centrum Menselijke Erfelijkheid, Herestraat 49 bus 602, 3000 Leuven, Belgium \\ ${ }^{\text {e }}$ Federal Public Service Health, Food Chain Safety and Environment, Place Victor Horta 40/10, 1060 Brussels, Belgium \\ f Flemish Institute for Technological Research (VITO), Boeretang 200, $2400 \mathrm{Mol}$, Belgium \\ ${ }^{\mathrm{g}}$ Department of Biomedical Sciences, University of Antwerp, Antwerp, Belgium \\ ${ }^{\text {h }}$ University of Southern Denmark, Odense, Denmark \\ i Environmental Toxicology, Centro Nacional de Sanidad Ambiental (CNSA), Instituto de Salud Carlos III (ISCIII), Ctra. Majadahonda-Pozuelo, km2, E- 28220 \\ Madrid, Spain \\ ${ }^{\mathrm{j}}$ Federal Environment Agency (UBA, Federal Environment Agency (UBA), Corrensplatz 1, 14195 Berlin, Germany \\ ${ }^{\mathrm{k}}$ University of Copenhagen, Department of Public Health, Øster Farimagsgade 5, DK 1353 Copenhagen K, Denmark \\ ${ }^{1}$ Departamento de Epidemiologia, Instituto Nacional de Saúde Dr. Ricardo Jorge, Lisboa, Portugal
}

\section{A R T I C L E I N F O}

\section{Article history:}

Received 7 November 2014

Received in revised form

19 March 2015

Accepted 21 March 2015

\section{Keywords:}

Environmental tobacco smoke

Human biomonitoring

Urinary cotinine

Cut-off value

Antismoking legislation
A B S T R A C T

The aim of this study was to explore data from the DEMOCOPHES study population for Romania, Portugal and Poland, in order to assess smoking patterns and the extent of ETS exposure and compare the national study samples with reference to the respective anti-smoking laws. The subset of the DEMOCOPHES study sample consisted of 360 children and their mothers (120 in each of the three countries - Romania (RO), Portugal (PT) and Poland (PL). Smoking was assessed using a detailed questionnaire for the participants, which addresses both active and passive smoking.

This assessment uses exposure-relevant questionnaire data, in particular on the home environment and residence, socio-demographic characteristics, lifestyle such as nutrition, smoking behavior, other exposure-relevant behavior and occupational history, as well as urinary cotinine and creatinine measurements. We performed general statistical analysis and innovative receiver operating characteristic (ROC) curve analyses.

Smoking prevalence as evaluated by the questionnaire was generally high, and higher than official statistics, which suggests some under-reporting in the countries, particularly in Romania. Urinary cotinine levels provided biochemical confirmation of the high and similar smoking prevalence for the three countries. Concerning ETS exposure, Romania presented significantly higher levels, for children as well as for non-smoking mothers, with Portugal showing significantly lower levels. Compared to non-smoking mothers, the children showed relatively higher ETS exposure levels in all three countries.

The established country-specific optimal cut-off values in urinary cotinine to distinguish smokers

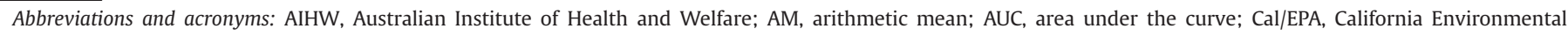
Protection Agency; CI, confidence interval; COPHES, Consortium to Perform Human Biomonitoring on a European Scale; DEMOCOPHES, Demonstration of a study to Co-

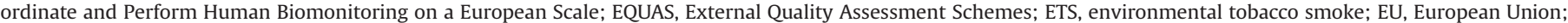
FCTC, Framework Convention on Tobacco Control; GATS, Global Adult Tobacco Survey; GATS, Global Adult Tobacco Survey; GerEs IV, German Environmental Survey for

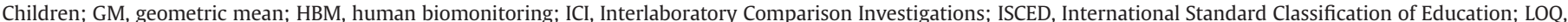

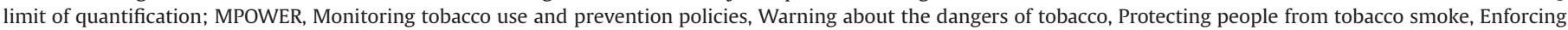
bans on tobacco advertising, promotion and sponsorship, Offering help to quit tobacco use, Raising tobacco taxes; ROC, receiver operating characteristic; SD, standard deviation; UAC, Union Against Cancer; UC, urinary cotinine; WHO, World Health Organization

* Corresponding author.

E-mail address: irlupsa@ehc.ro (I.-R. Lupsa).
} 
from non-smokers vary more than those to discriminate ETS exposure extent in non-smoking mothers and children. Although different between countries, these values are a valuable output to monitor effectiveness of both national antismoking laws and educational programs in the three countries.

The findings of this study point to the urgent need for stronger, more effective and well enforced smoke-free legislation in the three countries.

(c) 2015 Elsevier Inc. All rights reserved.

\section{Introduction}

Tobacco smoke and environmental tobacco smoke (ETS) are environmental toxicants, exposure to which involves a mixture of chemical substances, including the class of non-persistent semivolatile organic chemicals (Sexton and Ryan, 2012). More than 4000 chemicals, such as nicotine, polycyclic aromatic hydrocarbons, aromatic amines, and carbon monoxide, have been identified in tobacco smoke, among which more than 250 have been shown to be toxic (CDC, 2006) and at least 70 carcinogenic (CDC, 2014).

Research shows that although ETS exposure is a diluted form of exposure, certain toxic chemicals are present at higher proportions in ETS than in main-stream smoke. Exposure to freshly generated sidestream smoke has been reported to be approximately 4 times more toxic per gram of total particulate matter than mainstream smoke by inhalation (Schick and Glantz, 2005).

Based on accumulated evidence and copious new data, showing that ETS causes serious and fatal diseases in adults and children and that there is no safe level of exposure (WHO, 2007), a clear scientific consensus exists on the dangerous health effects of ETS exposure. Children exposed to ETS are at increased risk of developing asthma, sudden infant death syndrome, and ear and respiratory infections (CDC, 2006).

ETS represents a major source of indoor air pollution. Several relevant reports, including the 2004 monograph from the International Agency for Research on Cancer (IARC, 2004), the 2005 report from the California Environmental Protection Agency (Cal/ EPA) (Cal-EPA, 2005)) in the United States of America (US) and the 2006 report of the United States Surgeon General (CDC, 2006), have synthesized this evidence and also reached unambiguous and solid conclusions on the adverse health consequences, conclusions that provide a strong imperative for eliminating ETS exposure.

In its policy on protection against ETS exposure, the World Health Organization (WHO) strongly recommends compiling and disseminating this evidence (WHO, 2007). Likewise, Article 8 of the WHO Framework Convention on Tobacco Control (FCTC)-Protection from exposure to tobacco smoke-requires Parties to adopt and implement effective measures, for protection from ETS exposure (WHO, 2003, updated 2004, 2005).

In order to be able to prevent the harmful health effects, it is necessary to monitor the extent of exposure to tobacco smoke. This monitoring can be done by using questionnaires on smoking to obtain information on the number of cigarettes smoked per day and exposure-relevant behavior, as a cost-effective means of gathering data to develop an indicator of ETS exposure. However, people do not always admit they smoke, tending to under-report (Lewis et al., 2003). Moreover, even for correct reports, the variety of cigarette types (in terms of chemical components, nicotine levels and structure), of smoking behavior (how intensely cigarettes are smoked), and of ETS exposure determine the uptake of nicotine. This variety leads to different nicotine exposure amongst equal smoking status (Djordjevic et al., 1995; Chaiton et al., 2005; Connolly et al., 2007; Jain, 2014) and consequent misclassification of smokers/non-smokers and probably of ETS exposed/non-exposed, depending how the cigarette type and smoking behavior are reflected in the environmental constituents of tobacco smoke.

Thus, to obtain an accurately quantified exposure assessment, a biochemical determination is needed. Among the possible biomarkers, the preferred one for both active and environmental exposure to tobacco smoke is cotinine, the major proximate metabolite of nicotine (Jarvis et al., 1988; Benowitz 1996, 1999; UAC 2008; Benowitz et al., 2009a).

Although cotinine analysis can be performed using blood, urine, saliva, hair or toenail (Haufroid and Lison, 1998; Al-Delaimy et al., 2000; Etter et al., 2000; George et al., 2006; Man et al., 2009; Stepanov et al., 2007), urinary cotinine qualifies for a suitable indicator of ETS exposure due to well established advantages, and can be used to assess its future public health impact (Wall et al., 1988; Benowitz et al., 2009a; Tung et al., 2013).

However, cotinine level reflects exposure extent, dependent on external and internal factors (Hukkanen et al., 2005; Matt et al., 2006), not how (active/passive smoking) the exposure was derived (Benowitz et al., 2009a, 2009b). Overlaps can occur between less intense or less frequent active smokers and passive smokers, making it necessary to establish clear cotinine cut-off points to not only distinguish active from passive smokers, but also non-smoker ETS exposure categories, thus improving the accuracy of self-reported status and avoiding misclassification. Results from several studies suggest that the optimal cut-off levels to distinguish smokers from non-smokers in countries with effective smoke-free legislation might be much lower than in countries with low tobacco control status (Benowitz et al., 2009a, 2009b).

Romania (RO), Portugal (PT) and Poland (PL) are 3 out of the 17 European countries participating in the DEMOCOPHES (Demonstration of a study to Coordinate and Perform Human Biomonitoring on a European Scale) project. According to the Smokefree Partnership overview on the EU-smoke-free legislation in 2010 (SFP, 2011), the 3 countries score differently, in terms of the strength and enforcement of the respective anti-smoking laws, with a weak, unenforced law in bars, restaurants and workplaces in RO, an incomplete ban in bars and restaurants in PT and PL, and a complete ban in workplaces only in PL, although with ventilated smoking rooms permitted. Considering the summary indicators of country achievements for each of the MPOWER measures with comparable compliance scores available to WHO at end of 2012 (WHO, 2013), the following conclusions are evident: a lower smoking prevalence exists for PT (18.7\%) than for RO (24.3\%) and PL (27\%); PT scores higher (8) than PL and RO (7) with respect to protecting people from tobacco use; and all three countries have different scores for direct bans on tobacco advertising, promotion and sponsorship (10, 7, and 5, for RO, PT, and PL, respectively).

From a public health perspective, it is important to know whether and how the different national status on tobacco control is reflected in the active and passive smoking status in each country. To contribute to that knowledge, the specific objectives of this study were to explore data from the DEMOCOPHES study population from Romania, Portugal and Poland, in order to assess, 
in each national study sample and to compare between countries the smoking patterns, the ETS exposure extent, the urinary cotinine (UC) levels, and the misclassification of reported smoking status and extent of ETS exposure, according to the UC literature cut-off point. Another objective consisted in identifying the optimal UC country-specific cut-off points that distinguish smokers from non-smokers and non-smokers exposed to ETS from nonexposed, according to the smoking status and ETS exposure in the last $24 \mathrm{~h}$ before sampling, respectively.

\section{Material and methods}

Harmonized protocols have been used for recruitment, fieldwork, sample collection, analysis of biological material and data management, including statistical analysis. These protocols were elaborated in the COPHES (Consortium to Perform Human Biomonitoring on a European Scale) project and tested in the pilot study DEMOCOPHES (Joas et al., 2012; Casteleyn et al., in this issue; Bleakley et al., 2014).

\subsection{Study population, sampling and data collection}

The study population consisted of 120 children (6-11 yr) and their mothers ( $\leq 45 \mathrm{yr}$ ) in each of the 3 countries. The national mother-child pairs were recruited via schools from two sampling locations (60 in each location) with different degrees of urbanization, using the upper and lower category as urban and rural areas, respectively.

Fieldwork took place between September 2011 and January 2012. Based on a structured questionnaire referring to the participants' home environment and residence, socio-demographic data, lifestyle such as nutrition, smoking behavior, other exposurerelevant behavior, and occupational history data were collected from the mothers by trained fieldworkers in a face-to-face manner (on paper or Computer Assisted Personal Interview).

The question on exposure to environmental tobacco smoke (during the last $24 \mathrm{~h}$ before sampling, at home and elsewhere) was used to gather information on ETS exposure. Women who reported smoking daily or occasionally were classified as smokers and the self-reported never or former smokers, as non-smokers.

All mothers and children provided first morning urine samples, according to standardized procedures.

\subsection{Biomarker analysis}

Using validated methods (Schindler et al., 2014), cotinine and creatinine measurements in urine were performed by different "qualified laboratories" which had successfully participated in the external quality assessment exercises organized by COPHES, consisting in two Interlaboratory Comparison Investigations (ICI) and two External Quality Assessment Schemes (EQUAS). Detailed analytical methods are described elsewhere (De Cremer et al., 2013; Stragierowicz et al., 2013).

Shortly, a solution of cotinine-d3 was added to urine samples as an internal standard, and extraction with SPE on-line (Romania) or off-line method was carried out, followed by liquid chromatography separation and tandem mass spectrometry detection. Quantification of cotinine was done based on cotinine/cotinine-d3 ratio. The limit of quantification (LOQ) was $0.7 \mu \mathrm{g} / \mathrm{L}$.

Creatinine in urine was measured using the Jaffe method (Larsen, 1972).

\subsection{Statistical analysis}

Relevant questionnaire and biomarker data of the 3 countries were taken from the central database. Biomarker values below LOQ were replaced by $1 / 2$ LOQ. Samples with values $<300 \mathrm{mg}$ creatinine/L or $>3000 \mathrm{mg}$ creatinine/L were excluded from the statistical analysis (WHO, 1996). The general statistical analysis was performed following the common Statistical Analysis Plan developed by COPHES WP4 (Den Hond et al., 2015)

The main characteristics of the study population were summarized, both for the mothers and for the children, through the median, the 25th and 75th percentiles, and the maximum and minimum values (for continuous parameters), and frequencies and percentages (for the categorical), and compared between countries, using for numerical variables the One-way ANOVA test or its non-parametric alternative, Kruskal-Wallis test for numeric variables, and the Pearson's chi-squared test for categorical variables.

Urinary cotinine levels were determined by country and group of children and mothers, stratified by categories of smoking status (the mothers) and extent of ETS exposure in the last $24 \mathrm{~h}$ (the children and non-smoker mothers). The Kruskal-Wallis test and Pairwise Multiple Comparison Procedures-Dunn's Method, was performed to compare the median values of urinary cotinine between the three countries. Multiple-way ANOVA and multiple linear regression models were also adjusted to the base 10 logarithm of UC to compare UC levels between countries adjusted for age, body mass index and education.

Receiver operating characteristic (ROC) curve analysis is a graphical and quantitative technique that is increasingly used to determine the cut-off values for biomarkers of exposure to tobacco smoke (Benowitz et al., 2009a, 2009b; Goniewicz et al., 2011; Stragierowicz et al., 2013; Zielińska-Danch et al., 2007, 2009). The UC optimal country-specific cut-off values for smoking status and extent of ETS exposure are those urinary cotinine levels that maximize the total probability of correct classification in distinguishing non-smokers from smokers and ETS exposure strata of non-smokers in each country.

ROC curve analysis was used to identify the optimal cut-off values for each country, based on the measurement of uncorrected and creatinine-corrected UC levels and the dichotomous self-reported information in the countries, relative to smoking status and to ETS exposure during the $24 \mathrm{~h}$ before sampling. Overall accuracy was evaluated using the area under the curve (AUC), which shows the ability of the UC to correctly classify smoking status and ETS exposure extent, in the sense that a greater degree of separation between the UC distributions either among smokers/non-smokers or dichotomous ETS exposure strata of non-smokers will result in higher areas under the ROC curves. The optimal cut-off value for UC was the value associated with Youden's index (J), defined by: $\mathrm{J}=$ maximum [(sensitivity + specificity) - 1] (Perkins and Schisterman, 2006). To verify correctness of Youden's index calculation, every ROC curve was tested twice, taking into account discrimination of exposure as positive and as negative in second scenario, and the results did not vary.

The overall misclassification of self-reported smoking status based on UC levels encompasses the proportions of both self-reported non-smokers exceeding the UC cut-off point and self-reported smokers below that point, being computed as ( 1 - specificity) and (1 - sensitivity), respectively. In relation to ETS exposure extent, the overall misclassification based on UC levels is identically computed, using equivalent data from non-smokers that were reported as ETS exposed and as ETS non-exposed. For inter-country comparative purposes, the data on misclassification of both the self-reported smoking status and the ETS exposure extent were analyzed for each country, using the currently recommended and most widely used UC cut-off levels of $50 \mu \mathrm{g} / \mathrm{g}$ creatinine (Riboli et al., 1995) and $50 \mu \mathrm{g} / \mathrm{L}$ (Jarvis et al., 1987), hereinafter both generally designated as the "literature cut-off" point. 
The level of statistical significance was kept at $p<0.05$. The IBM program SPSS vs 20.0 (IBM SPSS) and the STATA 11.2 program were used for the statistical analysis.

\section{Results}

\subsection{Reported characteristics of the global study sample}

The most relevant characteristics of the studied population (children and their mothers) in the 3 countries are presented in Tables 1 and 2.

In total, 360 mother-child pairs were included, 120 from each country, equally divided between two national areas with different degree of urbanization, namely the urban and rural areas.

When comparing the mothers' demographic characteristics between countries (Table 1), statistically significant differences were found in the age and education distributions, with the Romanian slightly younger and more educated than the Portuguese and Polish mothers at the secondary, but not at the tertiary level.

Regarding body weight and height, significant differences were also found between countries, with Polish mothers presenting higher median weight and height than mothers from Romania and Portugal. Nevertheless, these differences were no longer significant when comparing the median levels of BMI.

The differences between countries in the distribution of studied mothers according to their smoking habits was marginally significant, indicating that mothers from Portugal have a higher prevalence of daily and occasional smokers (39.2\%) than those from Romania (30.8\%) and Poland (29.2\%). Regarding ETS exposure at home and elsewhere, significant differences were found between countries. Especially for exposure at home, a higher prevalence was found in Romania (28.9\% at home; $79.5 \%$ elsewhere) and Poland (25.9\% at home; 67.1\% elsewhere) than in Portugal (8.2\% at home; $46.6 \%$ elsewhere). Nevertheless, the frequency of ETS exposure in the last $24 \mathrm{~h}$ was not significantly different between the three countries.

Within the study group of the children from the 3 countries (Table 2), there was a good equilibrium between gender classes and age groups, meaning that there were no significant differences regarding gender and age. Differences between countries were however observed in the children's height, with the Romanian children presenting lower median height compared with the Portuguese and Polish, although the differences observed for body weight and BMI were not significant. Significant differences were also observed in the ETS exposure at home and elsewhere, in the same directions of the differences observed for the mothers, meaning that children in Poland and Romania presented higher frequency of ETS exposure than in Portugal. Equal to what was observed for the mothers, the frequency of ETS exposure of the children in the last $24 \mathrm{~h}$ was not significantly different between countries. Moreover, the prevalence of reported current ETS exposure in the children and in the mothers was of the same order of magnitude.

Table 1

Characterization of the mothers study population by country and global.

\begin{tabular}{|c|c|c|c|c|c|c|}
\hline Characteristics of study population & & Romania (RO) & Portugal (PT) & Poland (PL) & Global $(\mathrm{RO}+\mathrm{PT}+\mathrm{PL})$ & $P$ \\
\hline \multirow[t]{3}{*}{ Age, years } & Median ( $n)$ & $36(120)$ & $38(120)$ & $37(120)$ & $37(360)$ & $0.001^{*}$ \\
\hline & P25-P75 & $33-38$ & $35-41$ & $33-40$ & $34-40$ & \\
\hline & Min.-max. & $25-45$ & $26-45$ & $27-45$ & $25-46$ & \\
\hline \multirow[t]{3}{*}{ Age distribution } & $\leq 35$ years & $56 / 120(46.7 \%)$ & $36 / 120(30 \%)$ & $52 / 120(43.3 \%)$ & $144 / 360(40.0 \%)$ & $0.001^{* * * *}$ \\
\hline & $35-40$ years & $55 / 120(45.8 \%)$ & $53 / 120(44.2 \%)$ & $44 / 120(36.7 \%)$ & $152 / 360(42.2 \%)$ & \\
\hline & $\geq 40$ years & $9 / 120(7.5 \%)$ & $31 / 120(29.8 \%)$ & $24 / 120(20 \%)$ & $64 / 360(17.8 \%)$ & \\
\hline \multirow[t]{3}{*}{ Highest educational level of the family } & Primary (ISCED ${ }^{\mathrm{a}} 0-2$ ) & $14(11.7 \%)$ & $27(22.5 \%)$ & $27(22.5 \%)$ & $68(18.9 \%)$ & 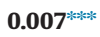 \\
\hline & Secondary (ISCED 3-4) & $60(50 \%)$ & $40(33.3 \%)$ & $35(29.2 \%)$ & $135(37.5 \%)$ & \\
\hline & Tertiary (ISCED 5-6) & $46(38.3 \%)$ & $53(44.2 \%)$ & $58(48.3 \%)$ & $157(43.6 \%)$ & \\
\hline \multirow[t]{3}{*}{ Body weight, kg } & Median $(n)$ & $61(120)$ & $60(120)$ & $65(120)$ & $62(360)$ & $0.003^{*}$ \\
\hline & P25-P75 & $55-70$ & $56-72$ & $60-75$ & $57-72$ & \\
\hline & Min.-max. & $35-112$ & $45-110$ & $46-107$ & $35-112$ & \\
\hline \multirow[t]{3}{*}{ Height, cm } & Median (n) & $164(120)$ & $163(120)$ & $166(120)$ & $164(120)$ & $0.002^{* * *}$ \\
\hline & P25-P75 & $160-167$ & $158.8-168$ & $162-170$ & $160-169$ & \\
\hline & Min.-max. & $147-178$ & $150-184$ & $150-181$ & $147-184$ & \\
\hline \multirow[t]{3}{*}{ Body-mass index, $\mathrm{kg} / \mathrm{m}^{2}$} & Median (n) & $23.4(120)$ & $24.3(120)$ & $23.6(120)$ & $23.2(360)$ & $0.096^{*}$ \\
\hline & P25-P75 & $20.8-26.0$ & $20.7-27.2$ & $21.5-26.8$ & $21.2-26.4$ & \\
\hline & Min.-max & $14.7-41.0$ & $17.0-41.0$ & $18.2-39.9$ & $14.7-41.2$ & \\
\hline \multirow[t]{4}{*}{ Smoking habits } & Daily smoker & $30 / 120(25 \%)$ & $36 / 120(30 \%)$ & $23 / 120(19.2 \%)$ & $89 / 360(24.7 \%)$ & $0.056^{* * \cdots * k}$ \\
\hline & Occasional smoker & $7 / 120(5.8 \%)$ & $11 / 120(9.2 \%)$ & $12 / 120(10.0 \%)$ & $30 / 360(8.3 \%)$ & \\
\hline & Former smoker & $19 / 120(15.8 \%)$ & $27 / 120(22.5 \%)$ & $16 / 120(13.3 \%)$ & $62 / 360(17.2 \%)$ & \\
\hline & Non-smoker (never) & $64 / 120(53.3 \%)$ & $46 / 120(38.3 \%)$ & $69 / 120(57.5 \%)$ & $179 / 360(49.7 \%)$ & \\
\hline \multirow[t]{2}{*}{ ETS $^{\mathrm{b}}$ exposure at home $\mathrm{c}^{\mathrm{cd}}$} & Yes & $24 / 83(28.9 \%)$ & $6 / 73(8.2 \%)$ & $22 / 85(25.9 \%)$ & $52 / 241(21.6 \%)$ & $0.002^{* * * *}$ \\
\hline & No & $59 / 83(71.1 \%)$ & $67 / 73(91.8 \%)$ & $63 / 85(74.1 \%)$ & $189 / 241(78.4 \%)$ & \\
\hline \multirow[t]{2}{*}{ ETS exposure elsewhere ${ }^{\mathrm{cd}}$} & Frequent & $66 / 83(79.5 \%)$ & $34 / 73(46.6 \%)$ & $57 / 85(67.1 \%)$ & $157 / 241(65.1 \%)$ & \\
\hline & 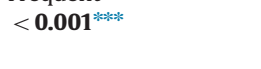 & Sometimes & $17 / 83(20.5 \%)$ & $39 / 73(53.4 \%)$ & $28 / 85(32.9 \%)$ & $\begin{array}{l}84 / 241 \\
(34.9 \%)\end{array}$ \\
\hline \multirow[t]{2}{*}{ ETS exposure in last $24 \mathrm{~h}^{\mathrm{d}}$} & Yes & $14 / 83(16.9 \%)$ & $18 / 73(24.7 \%)$ & $19 / 85(22.4 \%)$ & $51 / 241(21.2 \%)$ & 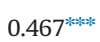 \\
\hline & No & $69 / 83(83.1 \%)$ & $55 / 73(75.3 \%)$ & $66 / 85(77.6 \%)$ & $190 / 241(78.8 \%)$ & \\
\hline
\end{tabular}

p-Value of comparison between countries.

* Kruskal-Wallis test.

**** Pearson's chi-squared test.

** One way ANOVA.

a ISCED: International Standard Classification of Education.

${ }^{b}$ ETS: Environmental Tobacco Smoke.

c $N=360$, for the 3 countries, and $N=120$, for each country, unless otherwise indicated.

${ }^{\mathrm{d}}$ For former and non-smokers only. 
Table 2

Characterization of the children study population by country and global

\begin{tabular}{|c|c|c|c|c|c|c|}
\hline \multicolumn{2}{|c|}{ Characteristics of study population } & \multirow{2}{*}{$\begin{array}{l}\text { Romania (RO) } \\
9(120)\end{array}$} & \multirow{2}{*}{$\begin{array}{l}\text { Portugal (PT) } \\
8(120)\end{array}$} & \multirow{2}{*}{$\begin{array}{l}\text { Poland (PL) } \\
8(120)\end{array}$} & \multirow{2}{*}{$\begin{array}{l}\begin{array}{l}\text { Global } \\
(\mathrm{RO}+\mathrm{PT}+\mathrm{PL})\end{array} \\
8(360)\end{array}$} & \multirow{2}{*}{$\begin{array}{l}P \\
0.895^{*}\end{array}$} \\
\hline Age, years & Median $(n)$ & & & & & \\
\hline & P25-P75 & $7-10$ & $7-10$ & $7-10$ & $7-10$ & \\
\hline & Min.-max. & $6-11$ & $5-11$ & $6-11$ & $5-11$ & \\
\hline \multirow[t]{2}{*}{ Age distribution } & $6-8$ years & $60 / 120(50.0 \%)$ & $62 / 120(51.7 \%)$ & $60 / 120(50 \%)$ & $182 / 360(50.6 \%)$ & $0.957^{* * *}$ \\
\hline & $9-11$ years & $60 / 120(50.0 \%)$ & $58 / 120(48.3 \%)$ & $60 / 120(50 \%)$ & $178 / 360(49.4 \%)$ & \\
\hline \multirow[t]{2}{*}{ Gender } & Boy & $58 / 120(48.3 \%)$ & $60 / 120(50 \%)$ & $60 / 120(50 \%)$ & $178 / 360(49.4 \%)$ & $0.957^{* * * *}$ \\
\hline & Girl & $62 / 120(51.7 \%)$ & $60 / 120(50 \%)$ & $60 / 120(50 \%)$ & $182 / 360(50.6 \%)$ & \\
\hline \multirow[t]{3}{*}{ Body weight, $\mathrm{kg}$} & Median $(n)$ & $30(120)$ & $31(120)$ & $32(120)$ & $31(120)$ & $0.367^{*}$ \\
\hline & P25-P75 & $25-35$ & $25-36$ & $25-40$ & $25-36$ & \\
\hline & Min.-max. & $16-54$ & $16-78$ & $18-60$ & $16-78$ & \\
\hline \multirow[t]{3}{*}{ Height, cm } & Median ( $n)$ & $131(120)$ & $135.2(120)$ & $136.9(120)$ & $133(360)$ & $<0.001^{* * *}$ \\
\hline & P25-P75 & $124.5-140$ & $126-144.3$ & $122-146$ & $125-144$ & \\
\hline & Min.-max. & $98-165$ & $108-164$ & $109-163$ & $98-165$ & \\
\hline \multirow[t]{3}{*}{ Body-mass index, $\mathrm{kg} / \mathrm{m}^{2}$} & Median $(n)$ & $17.4(120)$ & $16.6(120)$ & $16.7(120)$ & $17.5(360)$ & $0.349 *$ \\
\hline & P25-P75 & $15.3-19.5$ & $15.3-19.1$ & $15.2-18.7$ & $15.3-19.2$ & \\
\hline & Min.-max. & $12.5-30.0$ & $12.2-29.0$ & $10.7-30.61$ & $10.7-30.6$ & \\
\hline \multirow[t]{3}{*}{ ETS $^{\mathrm{a}}$ exposure at home $\mathrm{b}^{\mathrm{bc}}$} & Daily & $26 / 120(21.7 \%)$ & $18 / 120(15 \%))$ & $23 / 120(19.3 \%)$ & $67 / 360(18.7 \%)$ & $0.005^{* * * *}$ \\
\hline & Less than daily & $23 / 120(19.2 \%)$ & $6 / 120(5 \%)$ & $17 / 120(14.3 \%)$ & $46 / 360(12.8 \%)$ & \\
\hline & Never & $71 / 120(59.2 \%)$ & $96 / 120(80 \%)$ & $79 / 120(66.4 \%)$ & $246 / 360(68.5 \%)$ & \\
\hline \multirow[t]{2}{*}{ ETS exposure elsewhere ${ }^{\mathrm{bc}}$} & Frequent & $71 / 120(59.2 \%)$ & $50 / 120(41.7 \%)$ & $56 / 118(47.5 \%)$ & $177 / 358(49.4 \%)$ & $0.022^{\text {**** }}$ \\
\hline & Sometimes & $49 / 120(40.8 \%)$ & $70 / 120(58.3 \%)$ & $62 / 118(52.5 \%)$ & $181 / 358(50.6 \%)$ & \\
\hline \multirow[t]{2}{*}{ ETS exposure in last $24 \mathrm{~h}^{\mathrm{c}}$} & Yes & $28 / 120(23.3 \%)$ & $34 / 120(28.3 \%)$ & $32 / 120(26.7 \%)$ & $92 / 120(26.2 \%)$ & $0.668^{\text {**** }}$ \\
\hline & No & $92 / 120(76.7 \%)$ & $86 / 120(71.7 \%)$ & $88 / 120(73.3 \%)$ & $259 / 120(73.8 \%)$ & \\
\hline
\end{tabular}

$p: p$-value of comparison between countries

* Kruskal-Wallis test.

**** Pearson's chi-squared test.

** One way ANOVA.

a ETS: Environmental Tobacco Smoke.

${ }^{\mathrm{b}} N=360$, for the 3 countries, and $N=120$, for each country, unless otherwise indicated.

${ }^{\mathrm{c}}$ For former and non-smokers only.

Table 3

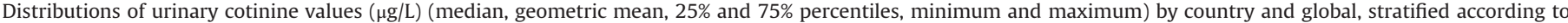
smoking status (all mothers) and ETS exposure in the last $24 \mathrm{~h}$ (non-smoking mothers and children).

\begin{tabular}{|c|c|c|c|c|c|c|c|}
\hline Characteristics of study population & & Romania (RO) & Portugal (PT) & Poland (PL) & Global $(\mathrm{RO}+\mathrm{PT}+\mathrm{PL})$ & $P$ & $P^{\#}$ \\
\hline \multicolumn{8}{|l|}{ All mothers, smoking status } \\
\hline \multirow[t]{4}{*}{ Smokers } & Median ( $n)$ & $1233.8(37)$ & $1294.5(47)$ & $952.8(35)$ & 1024.5 (119) & $0.544^{*}$ & $0.730^{* * \cdots}$ \\
\hline & Geometric mean & 540.1 & 602.5 & 455.9 & 536.5 & & \\
\hline & P25-P75 & $301.3-1701.9$ & 509.9-2006.7 & $550.8-1661.5$ & $442.3-1802.9$ & & \\
\hline & Min.-max. & $0.4-3848.5$ & $0.4-4796$ & $0.4-3525.0$ & $0.4-4796$ & & \\
\hline \multirow[t]{4}{*}{ Non-smokers } & Median $(n)$ & $1.4(80)$ & $0.4(73)$ & $0.9(85)$ & $0.8(238)$ & $<\mathbf{0 . 0 0 1}^{*}$ & 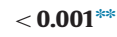 \\
\hline & Geometric mean & 3.6 & 0.8 & 1.2 & 1.5 & & \\
\hline & P25-P75 & $0.35-13.4$ & $0.35-0.9$ & $0.4-1.68$ & $0.35-2.3$ & & \\
\hline & Min.-max & $0.35-4513.3$ & $0.35-89.7$ & $0.4-1506.4$ & $0.35-4513.3$ & & \\
\hline \multicolumn{8}{|c|}{ Non-smoking mothers, ETS exposure last $24 \mathrm{~h}$} \\
\hline \multirow[t]{4}{*}{ Exposed } & Median $(n)$ & $7.4(13)$ & $1.0(18)$ & $3.2(19)$ & $3.1(50)$ & $0.001^{*}$ & $0.035^{* *}$ \\
\hline & Geometric mean & 9.2 & 1.6 & 7.7 & 4.6 & & \\
\hline & P25-P75 & $3.2-21.1$ & $0.4-6.1$ & $1.2-23.88$ & $1.2-14.2$ & & \\
\hline & Min.-max. & $1.3-242.4$ & $0.4-33.0$ & $0.40-1506.4$ & $0.35-1506.4$ & & \\
\hline \multirow[t]{4}{*}{ Non-exposed } & Median $(n)$ & $1.1(67)$ & $0.4(55)$ & $0.4(66)$ & $0.4(188)$ & $0.010^{*}$ & 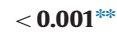 \\
\hline & Geometric mean & 2.9 & 0.6 & 0.7 & 1.1 & & \\
\hline & P25-P75 & $0.4-4.2$ & $0.4-0.8$ & $0.4-1.1$ & $0.4-1.4$ & & \\
\hline & Min.-max. & $0.4-4513.3$ & $0.4-89.7$ & $0.4-13.1$ & $0.4-4513.3$ & & \\
\hline \multicolumn{8}{|l|}{ Children, ETS exposure last 24 h } \\
\hline \multirow[t]{4}{*}{ Exposed } & Median $(n)$ & $8.7(28)$ & $2.2(34)$ & $7.4(32)$ & $6.1(94)$ & $<0.001^{*}$ & $<0.001^{\text {*** }}$ \\
\hline & Geometric mean & 7.9 & 2.4 & 7.8 & 5.1 & & \\
\hline & P25-P75 & $5.8-12.9$ & $0.9-8.2$ & $3.1-16.6$ & $1.9-12-4$ & & \\
\hline & Min.-max. & $0.8-52.4$ & $0.4-31.9$ & $0.8-88.5$ & $0.4-88.5$ & & \\
\hline \multirow[t]{4}{*}{ Non-exposed } & Median $(n)$ & $0.9(91)$ & $0.5(86)$ & $0.6(88)$ & $0.8(265)$ & $0.005^{*}$ & $0.002^{* *}$ \\
\hline & Geometric mean & 1.3 & 0.8 & 0.8 & 0.9 & & \\
\hline & P25-P75 & $0.4-2.8$ & $0.4-1.4$ & $0.4-1.5$ & $0.4-1.7$ & & \\
\hline & Min.-max & $0.4-31.9$ & $0.4-31.4$ & $0.4-10.9$ & $0.4-31.9$ & & \\
\hline
\end{tabular}

p-Value of comparison between countries.

* Kruskal-Wallis test.

*** Multiple-way ANOVA.

\# $p$ : $p$-value of comparison between countries obtained by multiple way ANOVA on the $\log _{10}$ of UC adjusted for confounders (age, body mass index and education level [except for children]). 

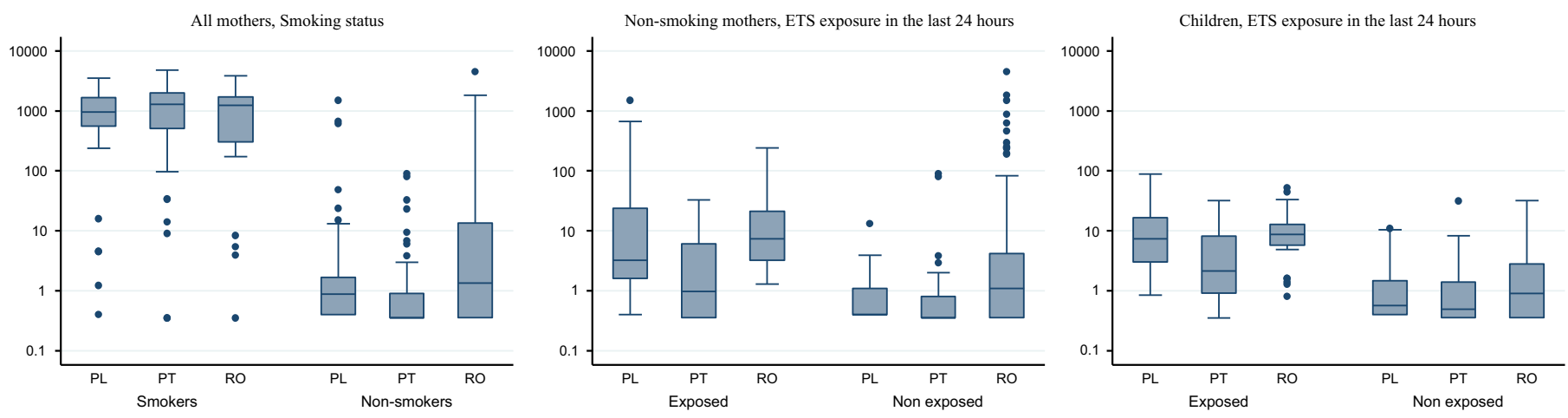

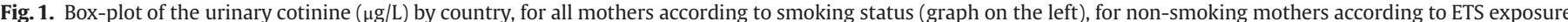
in the last $24 \mathrm{~h}$ (central graph) and for children according to ETS exposure in the last $24 \mathrm{~h}$ (graph on the right).

\subsection{Distribution of urinary cotinine levels according to smoking} habits and ETS exposure in the last $24 \mathrm{~h}$ by country (Romania, Portugal and Poland)

Urinary cotinine and creatinine were measured in all the valid samples of mothers and children of the study groups. Thus the statistical analysis was performed for data on cotinine from 357 mothers and 359 children and for data on cotinine/creatinine from 355 mothers and 352 children. In children, the geometric mean $(95 \% \mathrm{CI})$ for urinary uncorrected and creatinine-corrected cotinine equaled $1.49(1.12-1.98) \mu \mathrm{g} / \mathrm{L}$ and $\mu \mathrm{g} / \mathrm{g}$ creatinine. In mothers, including smokers and non-smokers, the UC levels were much higher compared to in children, equaling $10.98(8.27-14.58) \mu \mathrm{g} / \mathrm{L}$ and 9.10 (6.85-12.08) $\mu \mathrm{g} / \mathrm{g}$ creatinine.

According to Table 3 and Fig. 1, no statistically significant differences were observed in the UC levels distribution between countries within the smoking mothers group. Considering the group of the non-smokers, the UC levels distributions differ significantly $(p<0.001)$, with Romania presenting higher values than the other studied countries.

The countries differed significantly in both strata (exposed/ non-exposed) of the $24 \mathrm{~h}$ ETS exposure status within non-smoking mothers. Through not shown multiple linear regression models adjusted for age, body mass index and education (the last one only for mothers), Romania presents UC levels significantly higher than Poland and Portugal, among either the ETS exposed $(p=0.015)$ and the ETS non-exposed $(p<0.001)$ mothers.

In the same strata for children, significant differences were also found in UC levels distribution between countries. As observed for the non-smoking mothers, in Romania the children present higher UC levels when compared (also through multiple linear regression models) to those from each of the other two countries, either within the ETS exposed $(p<0.001)$ and the ETS non-exposed children $(p<0.001)$.

\subsection{Correlation between mother and child urinary cotinine levels according to smoking status of the mother by country (Romania, Portugal and Poland)}

As shown in Table 4 and Fig. S1, among the smoking mothers moderate to weak correlation levels were found between mother and child UC levels in each of the three countries. The lowest correlation coefficients were observed in Romania (rho $=0.284$; $p=0.889$ ), with results basically the same when UC creatininecorrected values were used.

Within the non-smoking mothers group, Spearman correlation coefficients were higher and statistically significant in all countries, ranging from 0.557 in Portugal to 0.739 in Poland.

\subsection{Urinary cotinine optimal cut-off values for ETS exposure and smoking status - the ROC curve analysis}

Concerning smoking status, all children were assumed to be non-smokers, as reported by their mothers. Furthermore and as shown in Table 5, among the study population with cotinine/ creatinine measurements, $67 \%$ of the mothers declared themselves to be former or never smokers, thus classified as non-smokers. ETS exposure in the $24 \mathrm{~h}$ before sampling was reported by $21 \%$ of the self-reported non-smoking mothers and $26 \%$ of the children with valid urine samples.

On the basis of these classifications and the corresponding uncorrected and creatinine-corrected UC levels, the country specific UC optimal cut-off values shown in Table 5 were calculated by the Youden's index and parameters of ROC curve analysis. These cut-off values distinguish smoker from non-smoker mothers in each country and, for children and their non-smoking mothers, ETS exposed from non-exposed in the last $24 \mathrm{~h}$, in each group and country. Since the optimal cut-off points are determined using as a reference reported smoking status (or ETS exposure extent), the reporting validity is determinant. Considerable misclassification

Table 4

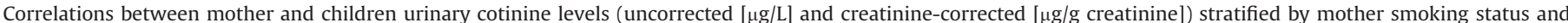
country.

\begin{tabular}{|c|c|c|c|c|c|c|}
\hline Mothers' smoking status & Units to express urinary cotinine data & Correlation statistics & Romania (RO) & Portugal (PT) & Poland (PL) & Global $(\mathrm{RO}+\mathrm{PT}+\mathrm{PL})$ \\
\hline \multirow[t]{4}{*}{ Smokers } & \multirow[t]{2}{*}{ Uncorrected urinary cotinine levels $(\mu \mathrm{g} / \mathrm{L})$} & Rho $(n)$ & $0.284(37)$ & $0.469(47)$ & $0.508(35)$ & 0.355 (119) \\
\hline & & $p$ & 0.889 & 0.009 & 0.002 & $<0.001$ \\
\hline & \multirow[t]{2}{*}{ Corrected urinary cotinine levels ( $\mu \mathrm{g} / \mathrm{g}$ creatinine) } & Rho $(n)$ & $0.224(37)$ & $0.609(47)$ & $0.581(34)$ & $0.489(118)$ \\
\hline & & $p$ & 0.184 & $<0.001$ & $<0.001$ & $<0.001$ \\
\hline \multirow[t]{4}{*}{ Non-smokers } & \multirow[t]{2}{*}{ Uncorrected urinary cotinine levels $(\mu \mathrm{g} / \mathrm{L})$} & Rho $(n)$ & $0.583(79)$ & $0.557(73)$ & $0.739(85)$ & $0.619(237)$ \\
\hline & & & $<0.001$ & $<0.001$ & $<0.001$ & $<0.001$ \\
\hline & \multirow[t]{2}{*}{ Corrected urinary cotinine levels ( $\mu \mathrm{g} / \mathrm{g}$ creatinine) } & Rho $(n)$ & $0.589(79)$ & $0.487(68)$ & $0.624(82)$ & $0.573(229)$ \\
\hline & & $p$ & $<0.001$ & $<0.001$ & $<0.001$ & $<0.001$ \\
\hline
\end{tabular}

Rho: Spearman's rank correlation coefficient; $n$ : number; $p$ : $p$-value for Spearman's rank correlation. 
Table 5

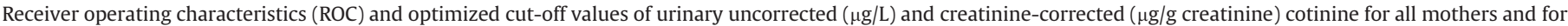
non-smoking mothers and children, using as reference the reported smoking status and ETS exposure in the last $24 \mathrm{~h}$, respectively.

\begin{tabular}{|c|c|c|c|c|c|c|c|c|c|}
\hline & & Groups & Countries & UC optimal cut-off value & Sensitivity (\%) & Specificity (\%) & Youden's index & AUC & $95 \% \mathrm{CI}$ \\
\hline \multirow[t]{8}{*}{ All mothers } & \multicolumn{9}{|c|}{ Smoking } \\
\hline & Yes & No & & Cotinine $(\mu \mathrm{g} / \mathrm{L})$ & & & & $p=0.395$ & \\
\hline & 35 & 85 & PL & 4.4 & 94.3 & 90.6 & 0.850 & 0.950 & $0.901-0.995$ \\
\hline & 47 & 73 & PT & 7.9 & 95.7 & 93.2 & 0.889 & 0.965 & $0.922-1.000$ \\
\hline & 37 & 80 & RO & $\begin{array}{l}254.2 \\
\text { Cotinine ( } \mu \mathrm{g} / \mathrm{g} \text { creatinine) }\end{array}$ & 83.8 & 91.3 & 0.750 & $\begin{array}{l}0.914 \\
p=0.729\end{array}$ & $0.853-0.975$ \\
\hline & 35 & 85 & PL & 24.8 & 88.6 & 94.1 & 0.827 & 0.947 & $0.899-1.000$ \\
\hline & 47 & 71 & PT & 6.1 & 95.7 & 94.4 & 0.901 & 0.958 & $0.907-1.000$ \\
\hline & 37 & 80 & RO & 165.8 & 89.2 & 87.5 & 0.767 & 0.928 & $0.875-0.982$ \\
\hline \multirow[t]{9}{*}{ Non smoking mothers } & \multicolumn{9}{|c|}{ ETS exposure } \\
\hline & Yes & No & & Cotinine $(\mu \mathrm{g} / \mathrm{L})$ & & & & $p=0.031$ & \\
\hline & 19 & 66 & PL & 1.4 & 84.2 & 84.9 & 0.691 & 0.892 & $0.809-0.975$ \\
\hline & 18 & 55 & PT & 1.2 & 50.0 & 87.3 & 0.373 & 0.697 & $0.550-0.843$ \\
\hline & 13 & 67 & RO & 2.7 & 92.3 & 73.1 & 0.654 & 0.760 & $0.659-0.862$ \\
\hline & & & & Cotinine $(\mu \mathrm{g} / \mathrm{g}$ creatinine) & & & & $p=0.401$ & \\
\hline & 19 & 66 & PL & 1.2 & 73.7 & 74.2 & 0.479 & 0.819 & $0.718-0.920$ \\
\hline & 17 & 54 & PT & 2.1 & 47.1 & 92.6 & 0.397 & 0.723 & $0.580-0.866$ \\
\hline & 13 & 67 & RO & 1.5 & 92.3 & 65.7 & 0.580 & 0.728 & $0.611-0.845$ \\
\hline \multirow[t]{9}{*}{ Children } & \multicolumn{9}{|c|}{ ETS exposure } \\
\hline & Yes & No & & Cotinine $(\mu \mathrm{g} / \mathrm{L})$ & & & & $p=0.005$ & \\
\hline & 32 & 88 & PL & 2.1 & 87.5 & 88.6 & 0.761 & 0.931 & $0.883-0.979$ \\
\hline & 34 & 86 & PT & 1.4 & 64.7 & 77.9 & 0.426 & 0.764 & $0.666-0.862$ \\
\hline & 28 & 91 & RO & 4.80 & 82.1 & 84.6 & 0.668 & 0.848 & $0.774-0.922$ \\
\hline & & & & Cotinine ( $\mu \mathrm{g} / \mathrm{g}$ creatinine) & & & & $\boldsymbol{p}=\mathbf{0 . 0 3 4}$ & \\
\hline & 31 & 85 & PL & 3.2 & 74.2 & 89.4 & 0.636 & 0.907 & $0.853-0.962$ \\
\hline & 33 & 84 & PT & 2.2 & 60.6 & 79.8 & 0.404 & 0.757 & $0.655-0.858$ \\
\hline & 28 & 91 & RO & 2.5 & 92.9 & 74.7 & 0.676 & 0.854 & $0.785-0.923$ \\
\hline
\end{tabular}

UC: Urinary cotinine; AUC: area under the curve; Youden's index =max (sensitivity + specificity - 1); $p$ : $p$-value for comparison of the AUC between countries.

would lead to a shift towards the right or to the left of one or both the UC levels distributions, depending on the type of misreporting, and to an over- or under-estimation of the optimal cut-off level.

To distinguish smokers from non-smokers, the optimal country-specific cut-offs varied from $4.45 \mu \mathrm{g} / \mathrm{L}$ in Poland to $254.15 \mu \mathrm{g} / \mathrm{L}$ in Romania and from $6.07 \mu \mathrm{g} / \mathrm{g}$ creatinine in Portugal to $165.8 \mu \mathrm{g} / \mathrm{g}$ creatinine in Romania, when based on uncorrected and creatininecorrected UC data, respectively. All AUC values were above 90\% and no statistical differences were found in AUC values between countries (Table 5 and Figs. S2 and S3), meaning that although the cut-offs are very different, the corresponding capacity to discriminate between smokers and non-smokers in the respective country is high and equivalent in the three countries.

On the contrary, the determined UC cut-off levels to distinguish ETS exposed from non-exposed children, although also different, had a much lower variation between countries (1.45 in Portugal to $4.80 \mu \mathrm{g} / \mathrm{L}$ in Romania and 2.15 in Portugal to $3.18 \mu \mathrm{g} / \mathrm{g}$ creatinine in Poland) and the discriminant capacity presented a significant variation $(p=0.005)$, with country specific AUC values ranging from 0.764 to 0.931 , respectively for Portugal and Poland. The same analysis using creatinine-corrected UC levels showed similar results, although lower variability between country-specific cutoffs. Since the poorest discriminant capacity is observed for the country with the lowest UC optimal cut-off point, this can be interpreted as reflecting for Portugal an approximation of the ETS exposed UC levels to those of the non-exposed.

The optimal cut-offs to distinguish ETS exposure categories of non-smoking mothers were very close to those obtained in children, although with less variability between countries (1.15 in Portugal to $2.65 \mu \mathrm{g} / \mathrm{L}$ in Romania and 1.16 in Poland to $2.09 \mu \mathrm{g} / \mathrm{g}$ creatinine in Portugal). AUC values varied significantly between countries when the uncorrected UC levels were used, but differences were no longer significant for creatinine-corrected values (Table 5).

Overall, these findings show that the optimal UC country-specific cut-offs are similar between children and non-smoking mothers, relatively reduced except for distinguishing smokers from non-smokers, and most often lower in Portugal.

\subsection{Misclassification of reported smoking status and ETS exposure extent}

To evaluate misclassification of reported smoking status and ETS exposure extent based on UC levels, the established optimal cut-off points and the "literature cut-off" were applied to the study sample from Romania, Portugal and Poland, separately for children and their mothers. Fig. 2 and Fig. S4 show the distributions of UC levels (uncorrected and corrected for creatinine) by country, proposed optimal UC group- and country-specific cut-off points and the UC literature cut-off for self-reported smoking and nonsmoking mothers (upper 3 graphs' panel) and for ETS exposure strata of non-smoking mothers and children, respectively in the central and bottom graphs' panels. An overlap (apparently different at the group and country level) is evident between corresponding UC distributions, with the UC levels for self-reported non-smokers, or for reported ETS non-exposed, spread over the range of the smokers or that of the ETS exposed, respectively. The reverse situation is also true. Overall, this means that there are UC levels above the corresponding group- and country-specific optimal cut-off values among both the women reported as non-smokers and the persons reported as ETS non-exposed (children and non-smoking mothers), but also UC levels of reported smokers and reported ETS exposed persons below those limits.

The misclassification of the groups was calculated using the literature cut-off and the distributions of unadjusted and creatinine-adjusted UC levels for each country and study group (Table 6).

Using unadjusted data, for the mothers self-reported as nonsmokers, the misclassification (given by the proportion of women with UC levels above the literature cut-off) varied from $2.7 \%$ (PT) to $17.5 \%$ (RO). This means that in Romania almost one in every five women (not smoking or misreporting their smoking status) had 

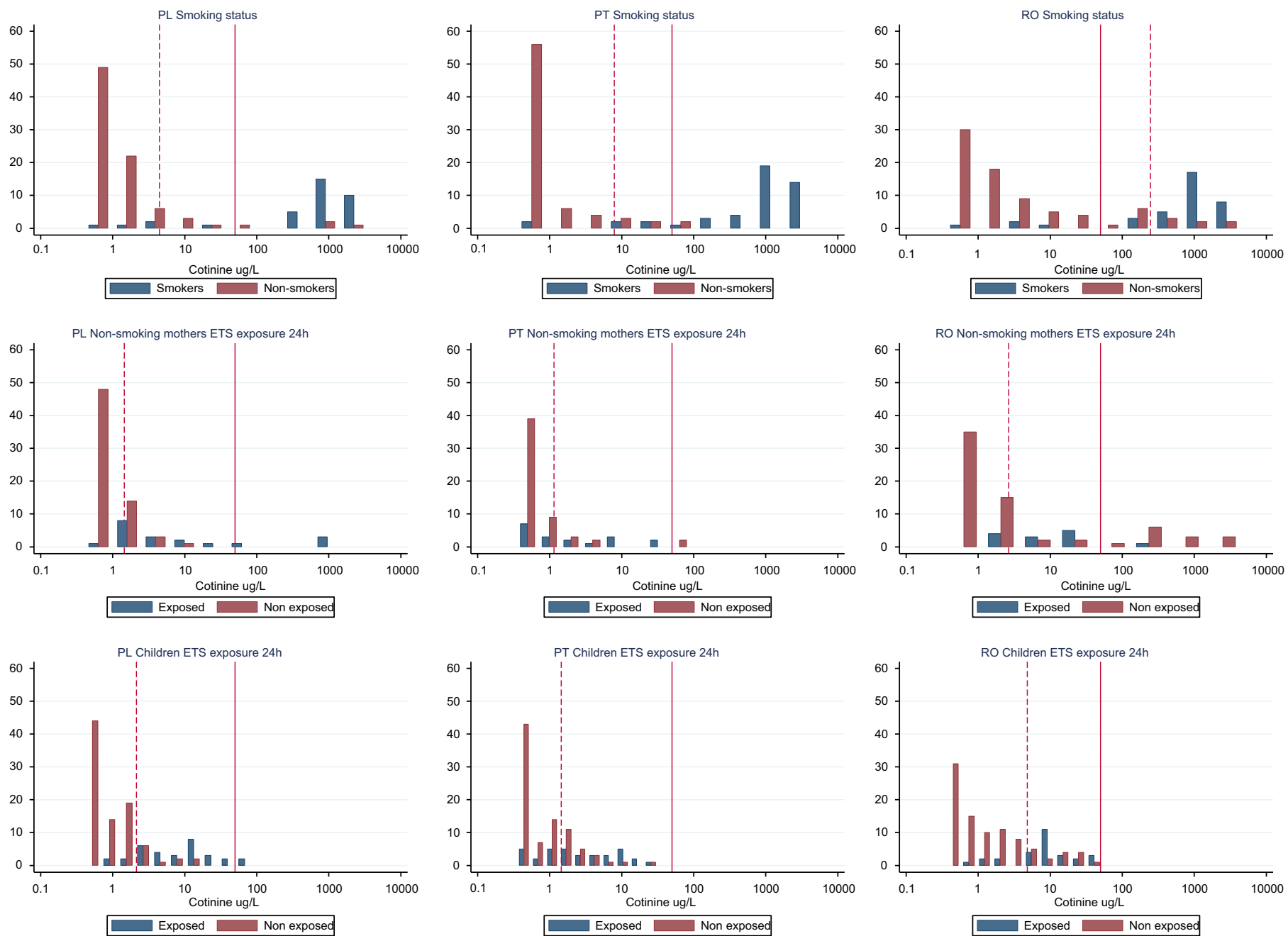

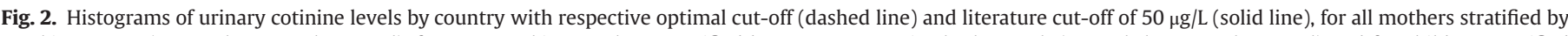

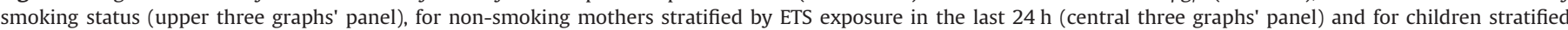
according to ETS exposure in the last $24 \mathrm{~h}$ (bottom three graphs' panel).

urinary cotinine levels typical of active smokers. Nonetheless, a proportion of self-reported smokers (lower in RO) had UC levels below the value that distinguishes smokers from non-smokers, probably reflecting less active smoking habits or heavy passive exposure to tobacco smoke (passive smokers).

Among the non-smoking mothers reported as ETS non-exposed, the misclassification rates varied from $0 \%$ in PL to $19.4 \%$ in RO. The misclassification rate for the children was zero in all countries. This means that none of the children reported as ETS non-exposed presented UC levels above the literature cut-off. Concerning mothers, and again in a more expressive way in $\mathrm{RO}$, a maternal misreporting or unknown heavy exposure to tobacco smoke was found, reflected in cotinine levels exceeding the limit for non-smokers. Among the same group and considering the mothers and the children reported as currently exposed to ETS, it was evident that, although the great majority had UC levels that did not reach the smokers/non-smokers cut-off point, there are children in Poland (6.3\%) and in Romania (3.6\%) exposed to ETS in the last $24 \mathrm{~h}$ before sampling, whose UC levels are so high that these identify them as smokers. This situation can also be observed for the mothers, in proportions of $7.7 \%$ in $\mathrm{RO}$ and $15.8 \%$ in PL. Portugal is the only studied country where none of the reported ETS-exposed non-smokers children or mothers presents UC levels above the literature cut-off point.

Using creatinine-corrected data, the findings are quite similar excepting that, also for Romania, none of the reported ETS-exposed children presents UC levels typical of smokers.

\section{Discussion}

\subsection{Main findings in relation to smoking and ETS exposure in the study sample}

Overall, 25.0, 19.2 and $30.0 \%$ of the mothers from Romania, Portugal and Poland, respectively, have reported smoking daily. Except for Portugal, these values are equal to or slightly lower than those for the general population in 2012 (shown in the "WHO Report on the Global Tobacco Epidemic, 2013"), which were 24.3, 18.7 and $27.0 \%$, respectively (WHO, 2013). Due to the non-representative nature of the study sample, the differences between the smoking prevalence registered in the WHO Report and observed in the national groups of mothers have to be interpreted with care. Nevertheless, the higher reported prevalence of ETS exposure at home and elsewhere for children and mothers found by this study in Romania and Poland when compared with Portugal could reflect the higher smoking prevalence shown by the WHO Report in these two countries, also pointing to a likely higher smoking under-reporting by the mothers from Romania and Poland than those from Portugal. 
Table 6

Misclassification rates of reported smoking status and ETS exposure extent of non-smoking mothers and children based on the UC "literature cut-off" point.

\begin{tabular}{|c|c|c|c|c|c|c|c|c|}
\hline \multirow[t]{2}{*}{ Units to express urinary cotinine } & \multirow[t]{2}{*}{ Groups } & & & \multirow[t]{2}{*}{ Countries } & \multicolumn{2}{|c|}{ UC "literature cut-off"a } & \multicolumn{2}{|c|}{ Misclassification rate (\%) } \\
\hline & & & & & Specificity (\%) & Sensitivity (\%) & $(1-\text { Specificity })^{b}$ & $(1-\text { Sensitivity })^{\mathrm{C}}$ \\
\hline \multirow{15}{*}{$\mu \mathrm{g} / \mathrm{L}$} & \multirow[t]{5}{*}{ All mothers } & \multicolumn{7}{|l|}{ Smoking } \\
\hline & & Yes & No & & & & & \\
\hline & & 35 & 85 & PL & 96.5 & 85.7 & 3.5 & 14.3 \\
\hline & & 47 & 73 & PT & 97.3 & 87.2 & 2.7 & 12.8 \\
\hline & & 37 & 80 & RO & 82.5 & 89.2 & 17.5 & 10.8 \\
\hline & \multirow[t]{5}{*}{ Non smoking mothers } & \multicolumn{7}{|c|}{ ETS exposure } \\
\hline & & Yes & No & & & & & \\
\hline & & 19 & 66 & PL & 100.0 & 15.8 & 0.0 & 84.2 \\
\hline & & 18 & 55 & PT & 96.4 & 0.0 & 3.6 & 100.0 \\
\hline & & 13 & 67 & RO & 80.6 & 7.7 & 19.4 & 92.3 \\
\hline & \multirow[t]{5}{*}{ Children } & \multicolumn{7}{|c|}{ ETS exposure } \\
\hline & & Yes & No & & & & & \\
\hline & & 32 & 88 & PL & 100.0 & 6.3 & 0.0 & 93.7 \\
\hline & & 34 & 86 & PT & 100.0 & 0.0 & 0.0 & 100.0 \\
\hline & & 28 & 91 & RO & 100.0 & 3.6 & 0.0 & 96.4 \\
\hline \multirow[t]{15}{*}{$\mu \mathrm{g} / \mathrm{g}$ creatinine } & \multirow[t]{5}{*}{ All mothers } & \multicolumn{7}{|l|}{ Smoking } \\
\hline & & Yes & No & & & & & \\
\hline & & 35 & 85 & PL & 96.5 & 85.7 & 3.5 & 14.3 \\
\hline & & 47 & 71 & PT & 97.2 & 87.2 & 2.8 & 12.8 \\
\hline & & 37 & 80 & RO & 83.8 & 89.2 & 16.2 & 10.8 \\
\hline & \multirow[t]{5}{*}{ Non smoking mothers } & \multicolumn{7}{|c|}{ ETS exposure } \\
\hline & & Yes & No & & & & & \\
\hline & & 19 & 66 & PL & 100.0 & 15.8 & 0.0 & 84.2 \\
\hline & & 17 & 54 & PT & 98.2 & 5.9 & 1.8 & 94.1 \\
\hline & & 13 & 67 & RO & 82.1 & 7.7 & 17.9 & 92.3 \\
\hline & \multirow[t]{5}{*}{ Children } & \multicolumn{7}{|c|}{ ETS exposure } \\
\hline & & Yes & No & & & & & \\
\hline & & 31 & 85 & PL & 100.0 & 6.5 & 0.0 & 93.5 \\
\hline & & 33 & 84 & PT & 100.0 & 0.0 & 0.0 & 100.0 \\
\hline & & 28 & 91 & RO & 100.0 & 0.0 & 0.0 & 100.0 \\
\hline
\end{tabular}

${ }^{a}$ UC literature cut-off is taken as $50 \mu \mathrm{g} / \mathrm{L}$, one of the most widely used UC cut-off point for uncorrected UC data (Jarvis et al., 1987), and 50 $\mu \mathrm{g} / \mathrm{g}$ creatinine, the currently recommended cut-off level for creatinine-corrected UC data (Riboli et al., 1995).

b Self-reported non-smokers or reported ETS non-exposed (non-smoking mothers or children).

c Self-reported smokers or reported ETS exposed (non-smoking mothers or children).

Except for smoking mothers, the median UC levels varied significantly between countries and in all strata (non-smoking mothers, ETS exposed and non-exposed mothers and children). Either for the children or for the non-smoking mothers, the differences observed between the countries' median UC levels suggest an ETS exposure in claimed non-smokers reflecting: (i) the lower national 2012 smoking prevalence in Portugal (WHO, 2013), compared with the corresponding values for the other two countries (also suggested by the above mentioned findings relative to the prevalence of reported ETS exposure in the study sample); (ii) the maternal smoking misreporting in Romania and Poland, already reported in other studies (Becker et al., 2003) and also suggested by the above ETS exposure findings; (iii) a potentially higher smoking prevalence in Romania than in Poland (also reported by the mothers of this study and statistically significant), which, by reference to the WHO Report and assuming that the differences between the Report's smoking prevalence for Romania and Poland are not by chance, is suggestive of a higher national smoking under-reporting in Romania than in Poland.

Within this context, it is notable that the moderate to high correlations between the UC levels of non-smoking mothers and their children at country level may reflect a relatively frequent common source of ETS exposure. Moreover, unless the maternal smoking under-reporting is a reality, especially in Romania, the children's passive smoking from the maternal smoking habits seems to be less likely, given the weak to moderate correlations between self-reported smokers and their children, in all countries, particularly in Romania.

This study found: (i) a smoking prevalence in the three countries that is higher in RO and lower in PT; (ii) a generalized exposure to ETS in the population of the three countries that follows the same order of the smoking prevalence; and (iii) a likely smoking status misreporting that seems to be also more common in RO than in PL and PT. Confirming the exposure to ETS of the general population of the three countries and the corresponding health risks, these findings point once more to the urgent need for implementing effective measures to reduce/control the ETS exposure in these countries.

Studies carried out worldwide on the effects of smoking bans on ETS showed that such policies result in considerable reductions in exposure to ETS, as well as in the improvement of health status (Pirkle et al., 2006). The investigations carried out by the US Center for Disease Control and Prevention (CDC) during the past decade comparing pre- and post-ban levels of serum cotinine in nonsmokers showed a reduction of approximately $70 \%$ (Pearson et al., 2009). Moreover, according to studies of nonresidential smokefree policies (Allwright et al., 2005; Farrelly et al., 2005; Fong et al., 2006; Haw and Gruer 2007) and those of the International Agency for Research on Cancer - IARC (IARC, 2009), only 100\% smoke-free measures are effective in reducing exposure to ETS and only total smoking ban in indoor spaces fully protects non-smokers from ETS exposure. The IARC studies also convincingly show that smokefree home policies reduce ETS exposure in children, reduce adult smoking and may reduce youth smoking.

All three countries of the present study signed the WHO Framework Convention on Tobacco Control (FCTC) in 2004 and ratification occurred in 2005 for Portugal and in 2006 for Romania and Poland (WHO, 2003). However, although these countries have 
adopted legislative and other measures aimed at limiting ETS exposure, the scope and character of those measures are different, thus giving different protection against ETS exposure and its harmful effects. The summary of MPOWER measures (WHO, 2013) shows that, as of 31 December 2012, smoke-free legislation in public places only covers health-care facilities in Romania and public transport in Poland, whilst in Portugal, in addition to these, also educational facilities (except universities outside of the buildings, according to the national 37/2007 Law) are included. Portugal also had a higher score for compliance with smoke-free legislation as well as advertising, promotion and sponsorship bans (covering both direct and indirect marketing), and a more complete national tobacco control program, with a national agency responsible for tobacco control objectives. It is then very likely that the different status of the WHO FCTC in the three countries may explain the lower national smoking prevalence of the Portuguese general population and thus the lower ETS exposure (as determined by the UC levels) of the children and non-smoking mothers in the more controlled public buildings (schools included) in the country. Even if speculatively (since, to the best of the authors knowledge, no study has yet shown confirmatory results), another factor that may contribute to explain this lower exposure to ETS of children and non-smoking mothers in PT may be the climate in general warmest in this country when compared with the other two. On the one hand, this better weather allow people to stay outdoors more frequently and for longer periods, therefore reducing the likelihood of being exposed to ETS; on the other hand, milder weather conditions mean that there may be better air exchange inside houses and enclosed public spaces, reflecting the greater frequency and duration of periods when the windows are open, which also may lead to a reduction in exposure to ETS even in homes and public spaces where there are smokers.

Although all three countries still have a long way to go to have more effective, comprehensive and 100\% smoke-free laws, the results of the comparative analysis between them already provide a valuable insight into the added value of more restrictive and effective legislation in Portugal, for the protection from exposure to tobacco smoke and consequent adverse health effects.

\subsection{UC cut-off levels and misclassification on smoking and ETS exposure}

The established country-specific optimal cut-offs to distinguish smokers from non-smokers presented a great variation, with the highest and lowest values differing by a factor of 57 or 7 , respectively, when based on uncorrected or creatinine-corrected UC data. Nonetheless, all AUC values were above $90 \%$ and no statistical differences were found in these values between countries, meaning that the capacity of each country-specific optimal cut-off in discriminating between smokers and non-smokers in the respective country is high and equivalent in the three countries.

For children and non-smoking mothers, the country-specific UC optimal cut-offs were very close, did not vary substantially between countries $(1.45-4.8 \mu \mathrm{g} / \mathrm{L}$ and $1.15-2.65 \mu \mathrm{g} / \mathrm{L}$, for uncorrected UC levels in children and mothers, respectively), and are generally similar to the 2 and $2.5 \mu \mathrm{g} / \mathrm{L}$ reported by other authors (Fustinoni et al., 2013; Man at al., 2009). Nevertheless, the efficiency of the test seems to vary with the country, mainly for children, since the corresponding AUC values present statistically significant differences, either for uncorrected or creatinine-corrected cotinine levels.

Overall, these findings show that the optimal UC country-specific cut-offs are similar among non-smoking mothers and children, relatively reduced (except for the smoking status), and most often lower in Portugal and higher in Romania, with lower sensitivity in Portugal. This means that the levels of the ETS exposed in Portugal "approximate" those of the non-exposed, leading to more reduced levels of exposure for those exposed. On the contrary, the levels of the ETS non-exposed in the other two countries, particularly in Romania, are shifted to higher values, "approximating" those of the exposed. This finding can reflect the statistically significant differences in exposure between the countries, not only with respect to the UC measured ETS levels, but probably also to the reported prevalence of exposure. It does not reflect however the (almost) significantly higher self-reported smoking prevalence in Portugal compared with the other two countries, suggesting again a higher misreporting, particularly in Romania, and a better accuracy of the WHO's Report (in comparison with the self-reported smoking status of the mothers' study sample) in representing the smoking prevalence relationship for the three countries.

With exception for the self-reported Romanian non-smokers, in all groups there is an improvement in correct classification of self-reported smoking status and ETS exposure extent by using the literature cut-off point. Furthermore, since the optimal cut-off points are determined using self-reported smoking status or reported ETS exposure extent as the gold standard, within a population (mainly from Romania), strongly suspected of misreporting mainly concerning smoking, for inter country comparative purposes, the literature cut-off seems to be the most reliable.

According to our findings, children and non-smoking women of the study sample from Romania, Poland and Portugal were exposed to ETS in the last $24 \mathrm{~h}$ before sampling, at such levels that some of them classify as active smokers. These findings and others relative to misclassification based on the literature cut-off reflect the lack of adequate tobacco control in the three countries, although at different levels, and support the process to enact and enforce $100 \%$ smoke-free legislation that bans smoking, thus preventing the pollutant (tobacco smoke) from affecting people's health (WHO, 2007). Protecting children from ETS exposure at places that are traditionally considered off limits to governmental or other outside intervention (homes, parents' cars and other private places) must also be addressed. Studies like ours, promoting awareness of the seriousness of the problem, are important first steps.

Findings on the optimal country- and group-specific cut-offs also strengthen the urgent need to enforce anti-smoking legislation and education, to improve health outcomes, particularly for children, but for the general population too, enforcements which can emulate the success of decreased blood lead levels since the ban of leaded gasoline.

Misreporting typically is related to cultural factors, level of social pressure in relation to tobacco control measures, and individual awareness on the risks associated with smoking and ETS exposure. It is very likely that this misclassification, due to misreporting, would not be comparable between countries. Although they can present similar values, the shifts in the distributions of the UC levels of each group and the respective over- or underestimation of the country-specific cut-offs may be related to different levels of the UC values, leading to a limited usefulness for inter country comparative purposes.

\section{Conclusions}

The DEMOCOPHES pilot study implemented in Romania, Poland and Portugal generated valuable information on smoking status and extent of exposure to tobacco smoke.

The findings of the study support public health policy-makers not only to enact and enforce legislation for $100 \%$ smoking ban in public places, but also to implement strategies and educational programs to reduce ETS exposure in the households and other 
private places.

The comparable UC optimal cut-off values between countries (both in non-smoking mothers and their children), or between corresponding cotinine and creatinine-adjusted values demonstrate the added-value of the harmonization of all included procedures, in particular those related to the questionnaires, field study organization, samples handling and the guaranty of the high quality of cotinine and creatinine measurements, which is the hallmark of the COPHES/DEMOCOPHES projects.

The cut-off levels established by this study, although useless for inter country comparative purposes, constitute a valuable output that can be used to monitor effectiveness of national anti-smoking and educational programs, designed to decrease exposure to and impact of ETS, one of the most preventable environmental pollutant, and to protect public environmental health in the context of a sustainable development. They may also be used to evidence the burden of disease attributable to ETS exposure in each country.

To support health decision-makers, the findings on misclassification are also good contributions, in the sense of providing an indication for action. Their relatively low level in relation to the maternal smoking status reflect reasonably accurate self-reporting among study participants, likely due to a natural lack of the high social and cultural pressure typically associated to strong, effective and strongly enforced smoke-free legislation. The probable reduced maternal awareness on the risks posed by the ETS exposure, the undervaluation or non-recognition of that exposure, and consequent under-reporting, may also be explained by the low/ moderate tobacco control status in the countries of the study population, something which again calls for the need of educational and awareness programs and promotion of effective antitobacco campaigns.

In terms of future prospects of this study, it is worth saying that some of the authors aim to gain access to data of all countries participating in the DEMOCOPHES Project, to extend the study to the largest possible number of countries with comparable data. The obvious advantages are, first and foremost, in terms of comparison of information on smoking and level of exposure to ETS from the 17 countries, some of them with a very different legislation on tobacco control. The results of this future study might constitute a much better support for the policy makers of public health in the fight to ensure the legitimate right to a smoke-free environment for all, especially for children.

\section{Financial support}

The research leading to these results has received funding for the COPHES project (COnsortium to Perform Human biomonitoring on a European Scale) from the European Community's Seventh Framework Programme. (DGResearch - No. 244237-COPHES)

DEMOCOPHES (DEMOnstration of a study to COordinate and Perform Human biomonitoring on a European Scale) was co-funded (50\%:50\%) by the European Commission LIFE + Programme LIFE + 2009(DG Environment - LIFE09ENV/BE000410-DEMOCOPHES), and the partners - The Environmental Health Center in Romania (EHC), the Faculdade de Medicina da Universidade de Lisboa (FMUL) in Portugal, and the Nofer Institute of Occupational Medicine (NIOM) and Ministry of Science and Higher Education in Poland.

For information on both projects as well as on the national cofunding institutions: see

http://www.eu-hbm.info/.

Ethics

The study was approved by the Ethical Committees in Romania, Portugal and Poland and an informed consent was signed by all participants.

\section{Acknowledgments}

We wish to thank the European Commission, DG for Research and Innovation (RTD), who funded COPHES in the 7th Framework Programme. DEMOCOPHES received funding through the LIFE+ financial instrument of the European Commision (DG ENV), as well as through funding received from different national institutions of the DEMOCOPHES countries (http://www.eu-hbm.info/democophes/project-partners). Finally, we would particularly like to thank all the mothers and children which so kindly and enthusiastic participated in this study.

\section{Appendix A. Supplementary material}

Supplementary data associated with this article can be found in the online version at http://dx.doi.org/10.1016/j.envres.2015.03. 018.

\section{References}

Al-Delaimy, W.K., Crane, J., Woodward, A., 2000. Questionnaire and hair measurement of exposure to tobacco smoke. J. Exp. Anal. Environ. Epidemiol. 10 (4), 378-384.

Allwright, S., PaulG, GreinerB., et al., 2005. Legislation for smoke- free workplaces and health of bar workers in Ireland: before and after study. Br. Med. J. 331 (7525), 1117. http://dx.doi.org/10.1136/bmj.38636.499225.55.

Becker, K., Schulz, C., Kaus, S., Seiwert, M., Seifert, B., 2003. German Environmental Survey 1998 (GerES III): environmental pollutants in the urine of the German population. Int. J. Hyg. Environ. Health 206 (1), 15-24.

Benowitz, N.L., 1996. Cotinine as a biomarker of environmental tobacco smoke exposure. Epidemiol. Rev. 18 (2), 188-204.

Benowitz, N.L., 1999. Biomarkers of environmental tobacco smoke exposure. Environ. Health Perspect. 107 (Suppl. 2), S349-S355.

Benowitz, N.L., Bernert, J.T., Caraballo, R.S., Holiday, D.B., Wang, J., 2009a. Optimal serum cotinine levels for distinguishing cigarette smokers and nonsmokers within different racial/ethnic groups in the united states between 1999 and 2004. Am. J. Epidemiol. 169 (2), 236-248.

Benowitz, N.L., Dains, K.M., Dempsey, D., Herrera, B., Yu, L., Jacob 3rd, P., 2009b. Urine nicotine metabolite concentrations in relation to plasma cotinine during low-level nicotine exposure. Nicotine Tob. Res. 11 (8), 954-960.

Bleakley, A., Hennessy, M., Mallya, G., Romer, D., 2014. Home smoking policies in urban households with children and smokers. Prev. Med. 62, 30-34 http://dx. doi.org/10.1016/j.ypmed.2013.12.015.

Cal-EPA (California Environmental Protection Agency), 2005. Proposed identification of environmental tobacco smoke as a toxic air contaminant. California Environmental Protection Agency, Air Resources Board, Sacramento, California http://www.oehha.org/air/environmental_tobacco/2005etsfinal.html (accessed 26.03.14.).

Casteleyn, L., Dumez, B., Becker, K., Kolossa-Gehring, M., Den, Hond, E., Schoeters, G., Castaño, A., Koch, H.M., Angerer, J., Esteban, M., Exley, K., Sepai, O., Bloemen, L., Horvat, M., Knudsen, L.E., Joas, A., Joas, R., Biot, P., Koppen, G., Dewolf, M.- C., Katsonouri, A., Hadjipanayis, A., Cerna, M., Krskova, A., Schwedler, G., Fid- dicke, U., Nielsen, J.K., Jensen, J.F., Rudnai, P., Kozepesy S., Mulcahy, M., Mannion, R., Gutleb, A.C., Fischer, M.E., Ligocka, D., Jakubowski, M., Reis, M.F., Namorado S., Lupsa, I.-R., Gurzau, A.E., Halzlova, K., Jajcaj, M., Mazej, D., Tratnik, J. S., Posada, M., Lopez, E., Berglund, M., Larsson, K., Lehmann, A., Crettaz, P., Aerts, D., 2014. A Pilot Study on the Feasibility of European Harmonized Human Biomonitoring: Challenges and Opportunities, this issue.

CDC (Centers for Disease Control and Prevention), 2006. 2006 Surgeon General's Report-The Health Consequences of Involuntary Exposure to Tobacco. CDC, AtlantGA 〈http://www.cdc.gov/tobacco/data_statistics/sgr/2006/index.htm〉 (accessed 26.03.14.).

CDC (Centers for Disease Control and Prevention), 2014. 2014 Surgeon General's Report: The Health Consequences of Smoking-50 Years of Progress 〈http:// www.cdc.gov/tobacco/data_statistics/sgr/50th-anniversary/index.htm〉.

Chaiton, M.O., Collinshaw, N.E., Callard, A.J., 2005. Smoker preference for "elastic cigarettes" in the Canadian cigarette market. Chronic Dis. Can. 26 (1), 20-24.

Connolly, G.N., Alpert, H.R., Wayne, G.F., Koh, H., 2007. Trends in nicotine yield in smoke and its relationship with design characteristics among popular US cigarette brands, 1997-2005. Tob. Control 16 (5), e5.

De Cremer, K., Van Overmeire, I., Van Loco, J., 2013. On-line solid-phase extraction with ultra performance liquid chromatography and tandem mass spectrometry for the detection of nicotine, cotinine and trans-3'-hydroxycotinine in urine to strengthen human biomonitoring and smoking cessation studies. J. Pharm. Biomed. Anal. 76, 126-133.

Den Hond E., Govarts E., Willems H., Smolders R., Casteleyn L., Kolossa-Gehring M. Schwedler G., Seiwert M., Fiddicke U., Castano A., Esteban M., Angerer J., Koch 
H.M., Schindler B.K., Sepai O., Exley K., Bloemen L., Horvat M., Knudsen LE, Joas A, Joas R., Biot P., Aerts D., Koppen G., Katsonouri A., Hadjipanayis A., Krskova A., Maly M., Mørck T.A., Rudnai P., Kozepesy S., Mulcahy M., Mannion R., Gutleb AC, Fischer ME, Ligocka D., Jakubowski M., Reis M.F., Namorado S, Gurzau AE, Lupsa I.-R., Halzlova K., Jajcaj M., Mazej D., Tratnik S.J., Lopez A., Lopez E., Berglund M., Larsson K., Lehmann A., Crettaz P., Schoeters G., 2015. The first steps towards harmonised human biomonitoring in Europe. EHP; 123 (3), 255-263, http://dx. doi.org/10.1289/ehp.1408616.

Djordjevic, M.V., Fan, J., Ferguon, S., Hoffmann, D., 1995. Self-regulation of smoking intensity. Smoke yields of the low-nicotine, low-'tar' cigarettes. Carcinogenesis 16 (9), 2015-2021.

Etter, J.F., Due, T.V., Perneger, T.V., 2000. Saliva cotinine levels in smokers and non smokers. Am. J. Epidemiol. 151 (3), 251-258.

Farrelly, M.C., Nonnemaker, J.M., Chou, R., Hyland, A., Peterson, K.K., Bauer, U.E., 2005. Changes in hospitality workers' exposure to secondhand smoke following the implementation of New York's smoke-free law. Tob. Control 14 (4), 236-241. http://dx.doi.org/10.1136/tc.2004.008839.

Fong, G.T., Hyland, A., Borland, R., et al., 2006. Reductions in tobacco smoke pollution and increases in support for smoke-free public places following the implementation of comprehensive smoke-free workplace legislation in the Republic of Ireland: findings from the ITC Ireland/UKSurvey. Tob. Control 15 (Suppl. 3), Siii51-S58. http://dx.doi.org/10.1136/tc.2005.013649.

Fustinoni, S., Campo, L., Polledri, E., Mercadante, R., Erspamer, L., Ranzi, A., Lauriola, P., Goldoni, C.A., Bertazzi, P.A., 2013. A validated method for urinary cotinine quantification used to classify active and environmental tobacco smoke exposure. Curr. Anal. Chem. 9 (3), 447-456. http://dx.doi.org/10.2174/ 1573411011309030014

George, L., Granath, F., Johansson, A.L.V., Cnattingius, S., 2006. Self-reported nicotine exposure and plasma levels of cotinine in early and late pregnancy. Acta Obstet. Gynecol. Scand. 85, 1331-1337.

Goniewicz, M.L., Eisner, M.D., Lazcano-Ponce, E., Zielinska-Danch, W., Koszowski, B., Sobczak, A., Havel, C., Jacob, P., Benowitz, N.L., 2011. Comparison of urine cotinine and the tobacco-specific nitrosamine metabolite 4-(methylnitrosamino)1-(3-pyridyl)-1-Butanol (NNAL) and Their ratio to discriminate active from passive smoking. Nicotine Tob. Res. 13 (3), 202-208. http://dx.doi.org/10.1093/ ntr/ntq237.

Haufroid, V., Lison, D., 1998. Urinary cotinine as a tobacco-smoke exposure index: a minireview. Int. Arch. Occup. Environ. Health 71 (3), 162-168. http://dx.doi.org/ $10.1007 / \mathrm{s} 004200050266$.

Haw, S.J., Gruer, L., 2007. Changes in exposure of adult non-smokers to secondhand smoke after implementation of smoke-free legislation in Scotland: national cross sectional survey. Br. Med. J. 335 (7619), 549. http://dx.doi.org/10.1136/ bmj.39311.550197.AE.

Hukkanen, J., Jacob, P., Benowitz, N.L., 2005. Metabolism and disposition kinetics of nicotine. Pharmacol. Rev. 57 (1), 79-115.

International Agency for Research on Cancer, 2004. Tobacco Smoke and Involuntary Smoking: Summary of Data Reported and Evaluation (IARC Monographs). Vol. 83. International Agency for Research on Cancer, Lyon http://monographs.iarc. fr/ENG/Monographs/vol83/ (accessed 26.03.14.).

International Agency for Research on Cancer, 2009. Evaluating the Effectiveness of Smoke-Free Policies (IARC Hand- Books of Cancer Prevention, Tobacco Control). Vol.13; 〈http://www.iarc.fr/en/media-centre/iarcnews/2009/IARChandbook13. php $\rangle$.

Jain, R.B., 2014. Trends in serum cotinine concentrations among daily cigarette smokers: data from NHANES 1999-2010. Sci. Total Environ. 472, 72-77. http: //dx.doi.org/10.1016/j.scitotenv.2013.11.002.

Jarvis, M.J., Tunstall-Pedoe, H., Feyerabend, C., Vesey, C., Saloojee, Y., 1987. Comparison of tests used to distinguish smokers from nonsmokers. Am. J. Public Health 77, 1435-1438. http://dx.doi.org/10.2105/AJPH.77.11.1435.

Jarvis, M.J., Russell, M.A., Benowitz, N.L., Feyerabend, C., 1988. Elimination of cotinine from body fluids: implications for noninvasive measurement of tobacco smoke exposure. Am. J. Public Health 78, 696-698.

Joas, R., Casteleyn, L., Biot, P., Kolossa-Gehring, M., Castano, A., Angerer, J., Schoeters, G., Sepai, O., Knudsen, L.E., Joas, A., Horvat, M., Bloemen, L., 2012. Harmonised human biomonitoring in Europe: activities towards an EU HBM framework. Int. J. Hyg. Environ. Health 215 (2), 172-175. http://dx.doi.org/10.1016/j. ijheh.2011.08.010.

Larsen, K., 1972. Creatinine assay by a reaction-kinetic principle. Clin. Chim. Acta 41, $209-217$.

Lewis, S.J., Cherry, N.M., McL Niven, R., Barber, P.V., Wilde, K., Povey, A.C., 2003. Cotinine levels and self-reported smoking status in patients attending a bronchoscopy clinic. Biomarkers 8 (3-4), 218-228.

Man, C.N., Fathelrahman, A.I., Harn, G.L., Lajis, R., Samin, A.S.M., Omar, M., Awang, R., Bayanuddin, N.A., 2009. Correlation between urinary nicotine, cotinine and self-reported smoking status among educated young adults. Environ. Toxicol. Phar 28 (1), 92-96.

Matt, G.E., Quintana, P.J., Liles, S., Hovell, M.F., Zakarian, J.M., Jacob 3rd, P., Benowitz,
N.L., 2006. Evaluation of urinary trans-3'-hydroxycotinine as a biomarker of children's environmental tobacco smoke exposure. Biomarkers 11, 507-523.

Pearson, J., Windsor, R., El-Mohandes, A., Perry, D.C., 2009. Evaluation of the immediate impact of the Washington, D.C., smoke-free indoor air policy on bar employee environmental tobacco smoke exposure. Public Health Rep. 124 (Suppl. 1), S134-S142.

Perkins, N.J., Schisterman, E.F., 2006. The inconsistency of "optimal” cut-points using two ROC based criteria. Am. J. Epidemiol. 163 (7), 670-675. http://dx.doi. org/10.1093/aje/kwj063.

Pirkle, J.L., Bernert, J.T., Caudill, S.P., Sosnoff, C.S., Pechacek, T.F., 2006. Trends in the exposure of nonsmokers in the U.S. population to secondhand smoke: 19882002. Environ. Health Perspect. 114, 853-858.

Riboli, E., Haley, N.J., Trédaniel, J., Saracci, R., Preston-Martin, S., Trichopoulos, D. 1995. Misclassification of smoking status among women in relation to exposure to environmental tobacco smoke. Eur. Respir. J. 8, 285-290.

Schick, S., Glantz, S., 2005. Philip Morris toxicological experiments with fresh sidestream smoke: more toxic than mainstream smoke. Tob. Control 14 (6) 396-404.

Schindler, B.K., Esteban, M., Koch, H.M., Castano, A., Koslitz, S., Cañas, A., Casteleyn, L., Kolossa-Gehring, M., Schwedler, G., Schoeters, G., Hond, E.D., Sepai, O., Exley, K., Bloemen, L., Horvat, M., Knudsen, L.E., Joas, A., Joas, R., Biot, P., Aerts, D., Lopez, A., Huetos, O., Katsonouri, A., Maurer-Chronakis, K., Kasparova, L., Vrbík K., Rudnai, P., Naray, M., Guignard, C., Fischer, M.E., Ligocka, D., Janasik, B., Reis, M.F., Namorado, S., Pop, C., Dumitrascu, I., Halzlova, K., Fabianova, E., Mazej, D. Tratnik, J.S., Berglund, M., Jönsson, B., Lehmann, A., Crettaz, P., Frederiksen, H. Nielsen, F., McGrath, H., Nesbitt, I., De Cremer, K., Vanermen, G., Koppen, G., Wilhelm, M., Becker, K., Angerer, J., 2014. 2014. The European COPHES/DEMOCOPHES project: towards transnational comparability and reliability of human biomonitoring results. Int. J. Hyg. Environ.Health. 217 (6), 653-661. http://dx.doi.org/10.1016/j.ijheh.2013.12.002.

Sexton, K., Ryan, A.D., 2012. Using exposure biomarkers in children to compare between-child and within-child variance and calculate correlations among siblings for multiple environmental chemicals. J. Expo. Sci. Environ. Epidemiol. 22 (1), 16-23. http://dx.doi.org/10.1038/jes.2011.30.

SFP, 2011, Smoke-free legislation in the EU. Available at: 〈http://www.smoke freepartnership.eu/smoke-free-legislation-eu> (accessed 29.04.14.)

Stepanov, I., Hecht, S.S., Lindgren, B., Jacob 3rd, P., Wilson, M., Benowitz, N.L., 2007. Relationship of human toenail nicotine, cotinine, and 4-(methylnitrosamino)-1(3-pyridyl)-1-butanol to levels of these biomarkers in plasma and urine. Cancer Epidemiol. Biomark. 16 (7), 1382-1386. http://dx.doi.org/10.1158/1055-9965. EPI-07-0145.

Stragierowicz, J., Mikołajewska, K., Zawadzka-Stolarz, M., Polańska, K., Ligocka, D., 2013. Estimation of cutoff values of cotinine in urine and saliva for pregnant women in Poland. Biomed. Res. Int. 2013, 386784. http://dx.doi.org/10.1155/ 2013/386784.

Tung, K.Y., Wu, K.Y., Tsai, C.H., Su, M.W., Chen, C.H., Lin, M.H., Chen, Y.C., Wu, W.C. Lee, Y.L., 2013. Association of time-location patterns with urinary cotinine among asthmatic children under household environmental tobacco smoke exposure. Environ. Res. 124, 7-12 http://dx.doi.org/10.1016/j.envres.2013.03. 002 .

Union Against Cancer (UAC), 2008. Protecting our children from second-hand smoke 2008. 〈http://www.uicc.org/programmes/protecting-our-childrenagainst-second-hand-smoke $\rangle$ (accessed 26.03.14.).

Wall, M., Johnson, J., Jacob, P., Benowitz, N., 1988. Cotinine in the serum, saliva and urine of nonsmokers, passive smokers, and active smokers. American Journal of Public Health 78 699-70.

WHO (World Health Organization), 2003 (updated 2004, 2005). WHO Framework Convention on Tobacco Control. Geneva, 〈http://whqlibdoc.who.int/publica tions/2003/9241591013.pdf, http://www.who.int/fctc/text_download/en/ (accessed 26.03.14.).

WHO, 1996. Biological Monitoring of Chemical Exposure in the Workplace, Geneva. /http://whqlibdoc.who.int/hq/1996/WHO HPR OCH 96.1.pdf).

WHO, 2007. Protection from exposure to second-hand tobacco smoke. Policy recommendations〈http://www.who.int/tobacco/resources/publications/wntd/ 2007/pol_recommendations/en/ $>$. (accessed 26.03.14.).

WHO Report on the Global Tobacco Epidemic, 2013. Enforcing bans on tobacco advertising, promotion and sponsorship 〈http://www.who.int/tobacco/global_ report/2013/en/> (accessed 26.03.14.).

Zielińska-Danch, W., Goniewicz, M.L., Szołtysek-Bołdys, I., Czogała, J., Koszowski, B., Słodczyk, E., Anczyk, E., Sobczak, A., 2009. Estimation of optimal levels of tobacco biomarkers to distinguish active and passive smokers using ROC analysis. Przegl. Lek. 66 (10), 636-640.

Zielińska-Danch, W., Wardas, W., Sobczak, A., Szołtysek-Bołdys, I., 2007. Estimation of urinary cotinine cut-off points distinguishing non-smokers, passive and active smokers. Biomarkers 12 (5), 484-496. 